\title{
IMPREMENTATION OF VGI-BASED GEOPORTAL FOR EMPOWERING CITIZEN'S GEOSPATIAL OBSERVATORIES RELATED TO URBAN DISASTER MANAGEMENT
}

\author{
Sanghoon Lee ${ }^{a *}$

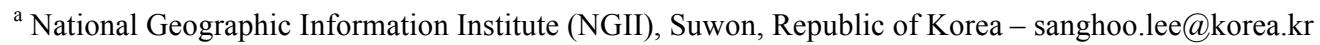

Commission II, ThS 14 - Recent Developments in Open Data

KEY WORDS: VGI, Public Participation, GeoPortal, Disaster Management, ISO/OGC Standard, UN-GGIM-AP

\begin{abstract}
:
The volunteered geospatial information (VGI) will be efficient and cost-effective method for generating and sharing large disasterrelated geospatial data. The national mapping organizations have played the role of major geospatial collector have been moving toward the considering public participation data collecting method. Due to VGI can conduct to encourage public participation and empower citizens, mapping agency could make a partnership with members of the VGI community to help to provide well-structured geospatial data. In order to effectively be understood and sharing the public semantics, datasets and action model of the public participation GeoPortal, the implemented VGI-GeoPortal designated as the basis of ISO 19154, ISO 19101 and OGC Reference Model. The proof of concepts of VGI-GeoPortal has been implemented urban flooding use-case in Republic of Korea to collect from the public, and analyze disaster-related geospatial data including high-disaster potential information such as the location of poor drainage sewer, small signs of occurring landslide, flooding vulnerability of urban structure, and etc.
\end{abstract}

\section{INTRODUCTION}

Many studies have shown that analysis capabilities based on GIS technology has enhanced decision making. Geospatial technologies support decision making in all phases of the disaster management cycle (Warfield, 2012). At the same time, it has been gradually understood that up-to-date geospatial data for disaster management, especially data during the response phase, is quite important. Besides geospatial data describing the disaster, information gathered from the citizens and other organizations are also valuable for emergency management and decision making.

The volunteered geospatial information (VGI) could be efficient and cost-effective method for generating and sharing large disaster-related geospatial data. When a disaster or emergency situation happens somewhere it includes the governmental and the public activities. The disaster preparedness and response phase of disaster management need GIS and GIS professionals to help decision makers identify vital reasons of the possible damage and assign response resource. Recently, the web, smart device and explosive spatially-related service- ubiquitous computing technologies - have ushered in a new era where the public are not only information consumers, but also act as producers of new, enriched information including disasterrelated geospatial data.

The national mapping organisations (NMOs) that have played the role of major geospatial collector have been moving toward the considering public participation data collecting methods. As VGI can act to encourage public participation and empower citizens, mapping agencies could make a partnership with members of the VGI community to help to provide well-structured geospatial data. In this regards, UN-GGIM-AP (United Nations on Global Geospatial Information Management - Asia-Pacific) introduce the idea of a VGI-based GeoPortal (VGI-GeoPortal) to provide cost-effective and real-time disaster-related information through collaboration with the public.

\section{RELEVANT REVIEWS FOR VGI}

With the advent and development of versatile mobile devices and Web-based GIS since 2000's, the general public now demands more geographic information than any other demographic group. With people generating, updating and maintaining their own geographic information voluntarily, the positional quality and logical consistency have been in doubt, which is why the VGI service providers have suggested a number of plans to secure reliability of geographic information. There is no doubt that VGI is drawing more attention than any time in the past, however, thanks to being cost-free, freedom in data use, promptness in use and varied subjects compared to the commercially available data. With the advent of Social Network Services (SNS) and growth of overall web-based environments, VGI not comprise the graphical and property information but also content-oriented data such as texts and images.

Representing VGI are Open Street Map(OSM) and Wikimapia. With OSM comprising a variety of sub-tier projects where the user-created maps are based. Mobile-based VGIs are also drawing attention, including the car-navigation application Waze and SNS-based Foursquare service. Variation of VGI data features a variety of subjects from the roadmap data, the base maps of the sub-tier information to POI data, such as popular restaurants, travel information and civil complaints data, video clips and images captured by drones, SNS-based location data, so on and so forth. Generating data on OSM is most common type of VGI which generates itself data by way of: data input onsite; uploading of data provided by the agencies or existing map data; or user's on-system edit. The data input is subject to onsystem calibration to make up for GPS error or position and property errors. VGI thus features the base maps where satellite video and digital map are provided for accurate calibration and editing.

The following table shows strengths and weaknesses between VGI and current for-profit service.

\footnotetext{
* Corresponding author
} 


\begin{tabular}{|c|c|c|}
\hline Service & Strengths & Weaknesses \\
\hline VGI & $\begin{array}{l}\text { *Cost-free } \\
\text { *Varied subjects } \\
\text { compared to the } \\
\text { commercially } \\
\text { available data } \\
\text { *Promptness in } \\
\text { generation of data } \\
\text { *Promptness in data } \\
\text { upgrades } \\
\text { *Multiple users } \\
\text { involving in data } \\
\text { generation } \\
\text { *Use of varied data is } \\
\text { unrestricted }\end{array}$ & $\begin{array}{l}\text { *Problem of } \\
\text { positional quality due } \\
\text { to lack of } \\
\text { professionalism } \\
\text { *Logical } \\
\text { inconsistency due to } \\
\text { subjectivity } \\
\text { *Malignant } \\
\text { participants }\end{array}$ \\
\hline $\begin{array}{c}\text { For- } \\
\text { profit } \\
\text { Service }\end{array}$ & $\begin{array}{l}\text { * Positional quality } \\
\text { thanks to } \\
\text { professionals and } \\
\text { cutting-edge } \\
\text { equipment } \\
\text { * Logical consistency } \\
\text { * Reliability in data }\end{array}$ & $\begin{array}{l}\text { *Purchase of data } \\
\text { costs a lot } \\
\text { *Update is required } \\
\text { on a regular basis } \\
\text { * Restricted use due to } \\
\text { security affairs }\end{array}$ \\
\hline
\end{tabular}

Table 1. Comparison between VGI and for-profit service

\section{SYSTEM DESIGN \& IMPLEMENTATION OF VGI- GEOPORTAL FOR URBAN FLOOD PREVENTION}

For disaster prevention, the government is making systematic efforts to support the execution of public policies that can be used to raise awareness of natural disasters in the community; the general public have to have the opportunity to understand the influences caused by natural disasters; and the community should be leading and active in forming the awareness of the community-based disaster preparation. There are efforts to establish urban flood prevention database through combination of data in various systems promoted by the government and at the same time, user VGI-GeoPortal can be established through the community mapping participated by citizens.
Community mapping is a compound word of 'community' and 'mapping.' 'Community' indicates all the people who live in a particular area or place and so is a spatial and regional unit of a social organization and in this sense, refers to psychological association or sense of belonging related to such a unit. 'Mapping' indicates mapping work. In other words, it connects information to place by making visual expression of the information on geography and space. To combine the two words above into one, 'Community Mapping' can be said as an expression of the common interests by the people who have similar geographical association and sense of belonging into maps.

VGI-GeoPortal is necessary to respond to mega disaster by considering local characteristics about disaster vulnerability. Through VGI-GeoPortal, the stakeholders can quickly obtain the disaster damage information updated by citizens and generate the response strategy based on proper contextual information. To increases the usability of response strategy and secure the power of execution, VGI data should be connected with the authorized data managed by National Mapping Agency or Disaster Management Agency.

In order to effectively be understood and sharing semantics, datasets and business model of GeoPortal among various stakeholders, The VGI-GeoPortal for Disaster Management architecture needs to be designated as developing process standard, RM-ODP: ISO/IEC10746, Information technology Open Distributed Processing - Reference model. The RM-ODP standards are used in multiple geospatial and related portal architectures, e.g. the ISO19100 series of geographic information/geomatics standards, and the OGC Reference Model. The RM-ODP design process is also in line with the existing efforts of numerous Spatial Data Infrastructures (SDIs) efforts that work towards providing geospatial services. RMODP defines five viewpoints that separate the various concerns in developing architecture.

According to the developing process of RM-ODP standards, the GeoPortal architecture has to be involved in information framework, services, component types and use-cases. The information framework is identified as the basis of ISO 19154 Geographic Information-Ubiquitous Public Access-Reference Model, and the reference of ISO 19101 Geographic Information

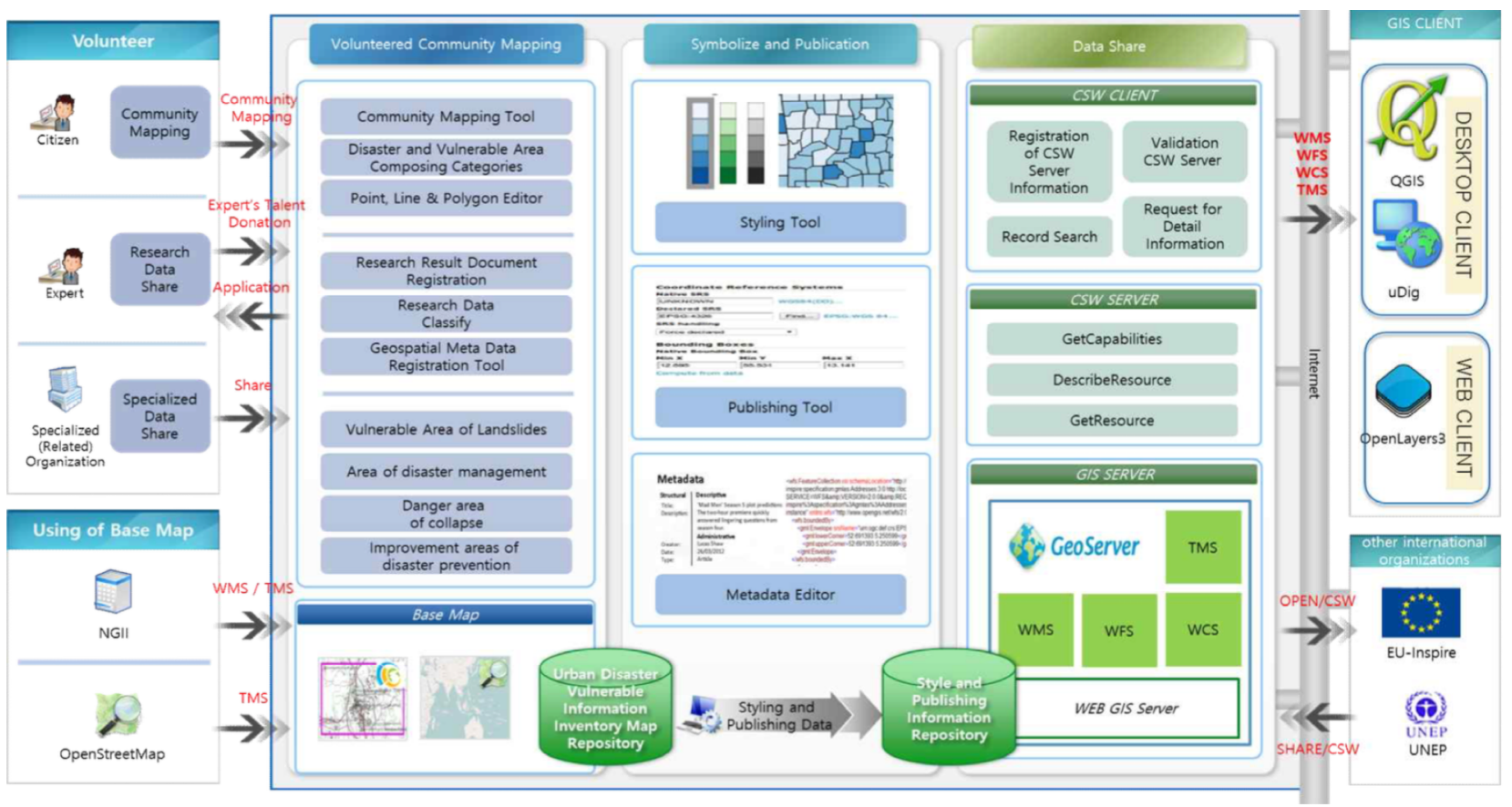

Figure 1. System structure for VGI-GeoPortal for Disaster Management 
- Reference Model and OGC Reference Model. Services and Component types is described as ISO 19119 Geographic Information - Services and the components of OGC Geospatial Web service standards.

The service component of VGI-GeoPortal could be identified as implementable standards in the basis of the Open-Source GIS and SOA (Service-oriented Architecture), e.g. GeoServer, the Geospatial Web Service standards of OGC shown as figure 1. The proof of concept of a VGI-GeoPortal has been implementing for an urban flooding use-case in Republic of Korea to collect data from the public, and analyse disaster-related geospatial data including high-disaster potential information such as the location of poor drainage sewer, small signs of landslides occurring, flood vulnerability of urban structures etc.

The VGI data produced by users (points, lines, polygons) can be added, edited and deleted via WFS Transaction Service, an OGC standard service, for data storage. Simulation data from urban disaster prevention experts can be capitalized on, by way of geographic information data upload/download functions and CSW-based data-sharing. Also, VGI data generated by either community or field experts can be transferred, via CSW to the CSW server and client. Geospatial data from outside agencies and international organizations can be inquired, accumulated and utilized in the VGI via CSW client. Geospatial service server compatible with OGC CSW helps realize metadata request, indepth record inquiry and request of records to share and utilize the outside data from the field experts to the maximal extent.

The figure 2 and 3 which describe web application for view/edit and mobile application for input respectively are implementation of VGI-GeoPortal for Urban disaster management according to mentioned design structure.

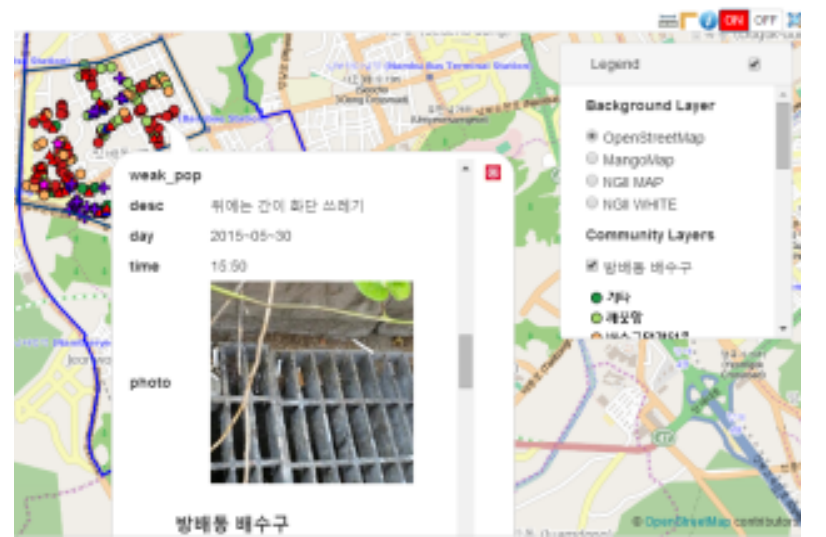

Figure 2. Implementation of Web Portal (View/Edit, Analysis)

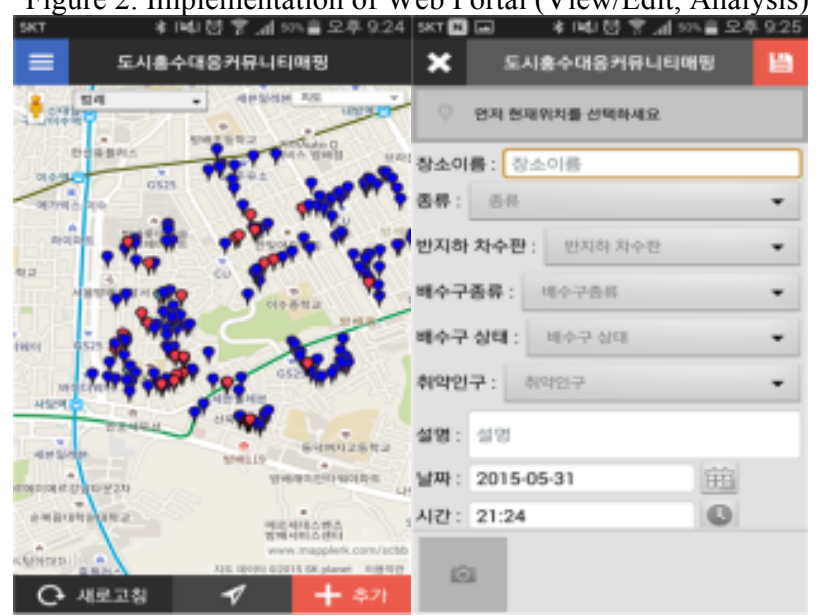

Figure 3. Implementation of Mobile Application (Input)

\section{PRELIMINARY DISCUSSIONS FOR VGI QUALITY}

According to the survey of UN-GGIM (Sanghoon, 2015), many countries don't promote VGI yet but the awareness about the importance of VGI has gradually increased. The main purposes of NMOs to use VGI are to detect and collect changes on maps, reduce costs of data collection, satisfy users' needs, and so on. The advantages of VGI are understood as easily updating the newest data, increasing the speed of data collection, and so on by NMO. But there have been proved major concerns for data quality from VGI generating process.

Generally, supply-centered geographic information data establishment and service development involves such limitations of information as newness, diversity, and availability. To overcome such limitations, many efforts have recently been made to utilize user experience and participation-based geographic information into geographic information web service. To respond to urban flood, this paper utilizes community mapping and based on VGI, demonstratively establishes a urban flood prevention and sharing portal in OOOO-dong, Seoul.

In order to improve quality of VGI concerned by many people, you will need to understand that accuracy means wholly different from purpose to purpose and thus define the unit of data to fit the subject and purpose, implementation sequence for data generation and quality control activities as follows:

- Definition of unit of data: define clarity in community subject, layer for the desired subject and individual features that fit the desired layer;

- Implementation sequence: implementation of spatial data generation, addition, edit and deletion;

- Quality control and maintenance: automated input and verification support or tool, and categorization and evaluation of generated VGI data

\section{REFERENCES}

Sanghoon Lee, 2015. Community mapping and quality assurance for urban disaster mapping. UN-GGIM NIA Working Group meeting, NewYork, USA.

Warfield, C., 2012. "The Disaster Management Cycle", http://www.gdrc.org/uem/disasters/1-dm_cycle.html (26 Apr. 2016). 